\title{
The Impact of the Surgical Apgar Score On Oncological Outcomes in Patients With Colorectal Cancer: A Single- Center Retrospective Cohort Study
}

\author{
Atsushi Sugimoto \\ Osaka City University: Osaka Shiritsu Daigaku https://orcid.org/0000-0003-3311-2562 \\ Tatsunari Fukuoka ( $\square$ achieve_h_h_0826@yahoo.co.jp) \\ Osaka City University: Osaka Shiritsu Daigaku \\ Hisashi Nagahara \\ Osaka City University: Osaka Shiritsu Daigaku \\ Masatsune Shibutani \\ Osaka City University: Osaka Shiritsu Daigaku \\ Yasuhito Iseki \\ Osaka City University: Osaka Shiritsu Daigaku \\ Maho Sasaki \\ Osaka City University: Osaka Shiritsu Daigaku \\ Yuki Okazaki \\ Osaka City University: Osaka Shiritsu Daigaku \\ Kiyoshi Maeda \\ Osaka City General Hospital: Osaka Shiritsu Sogo Iryo Center \\ Masaichi Ohira \\ Osaka City University: Osaka Shiritsu Daigaku
}

\section{Research Article}

Keywords: surgical Apgar score, colorectal cancer, postoperative complications, prognosis, cancer specific survival

Posted Date: November 3rd, 2021

DOI: https://doi.org/10.21203/rs.3.rs-1029148/v1

License: @ (i) This work is licensed under a Creative Commons Attribution 4.0 International License. Read Full License 


\section{Abstract}

Background: The surgical Apgar score (SAS) predicts postoperative complications (POCs) following gastrointestinal cancer surgery. Recently, the SAS was reported to be a predictor of not only POCs but also the prognosis. However, the impact of the SAS on oncological outcomes in patients with colorectal cancer (CRC) has not been fully examined. The present study therefore explored the oncological significance of the SAS in patients with CRC.

Methods: We retrospectively analyzed 639 patients who underwent radical surgery for CRC. The SAS was calculated based on three intraoperative parameters: estimated blood loss, lowest mean arterial pressure and lowest heart rate. The optimal cut-off value of the SAS was determined by receiver operating characteristic curves. All patients were classified into 2 groups based on the SAS ( $\leq 6$ and $>6$ ). The association of the SAS with the recurrence-free survival (RFS), overall survival (OS) and cancer-specific survival (CSS) was analyzed.

Results: Univariate analyses revealed that a lower SAS $(\leq 6)$ was significantly associated with a worse RFS, OS and CSS. A multivariate analysis revealed that age $\geq 75$ years old, Charlson comorbidity index $\geq 1$, ASA-Physical Status $\geq 3$, SAS $\leq 6$, histologically undifferentiated tumor type and an advanced pStage were independent factors for the OS, and an SAS $\leq 6$ and advanced pStage were independent factors for the CSS.

Conclusions: A lower SAS $(\leq 6)$ was an independent prognostic factor for not only the OS but also the CSS in patients with CRC, suggesting that the SAS might be a useful biomarker predicting oncological outcomes in patients with CRC.

\section{Introduction}

Colorectal cancer (CRC) was estimated to account for more than 1.9 million new colorectal cancer cases and 935,000 deaths in 2020, ranking third in terms of incidence but second in terms of mortality globally [1]. Although surgical resection is standard treatment for local and regional $\mathrm{CRC}$ worldwide, the mortality from $\mathrm{CRC}$ remains unsatisfactory.

Notably, among patients who undergo curative surgery for CRC, approximately one-third will develop disease recurrence, underscoring the importance of developing biomarkers to identify patients who may require postoperative intensification of treatment[2]. Postoperative complications (POCs) are reportedly significantly associated with a poor prognosis in CRC [3]. Therefore, predicting and preventing POCs might be one way to increase the survival in CRC.

The surgical Apgar score (SAS) system was developed by Gawande et al. to predict POCs in general surgery in 2007 [4]. The SAS consists of three intraoperative parameters: the estimated blood loss (EBL), lowest mean arterial pressure (LMAP) and lowest heart rate (LHR). The SAS has been validated as a predictor of POCs in CRC surgeries [5]. Previously, we reported that the SAS was a valuable predictor of severe complications after CRC surgery in elderly patients [6]. One reason why the SAS is able to predict POCs is that it reflects the intraoperative hemodynamic stability in patients with gastrointestinal cancer. Recent studies have highlighted the significant impact of the SAS on not only POCs but also the overall survival (OS) in gastrointestinal cancer $[7,8]$. However, the impact of the SAS on oncological outcomes in patients with CRC has not been fully examined.

We hypothesized that the SAS, which reflects intraoperative hemodynamics, would affect not only the OS but also the oncological long-term outcomes, such as the recurrence-free survival (RFS) and cancer-specific survival (CSS), in CRC patients. The present study therefore assessed the impact of the SAS on oncological outcomes after radical surgery in CRC patients.

\section{Materials And Methods}

\section{Patients}


We retrospectively analyzed consecutive patients who underwent radical surgery under general anesthesia for CRC at the Department of Gastroenterological Surgery, Osaka City University Hospital from January 2008 to December 2014. We

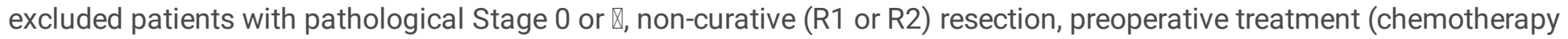
and/or radiotherapy), synchronous surgeries for other cancers and histologically atypical tumors, such as squamous cell carcinoma, small-cell carcinoma, gastrointestinal stromal tumor (GIST) or melanoma. The following clinical and surgical data were collected from electronic medical records: age, gender, body mass index (BMI), the presence of current smoking, the Glasgow prognostic score (GPS) based on preoperative serum albumin and C-reactive protein (CRP) levels [9], the American Society of Anesthesiologists classification of physical status (ASA-PS), tumor location (colon and rectum), pathological T ( $\mathrm{pT}$ ) stage, pathological $\mathrm{N}(\mathrm{pN})$ stage, pathological TNM stage (pStage), histological tumor type (differentiated type; well- or moderately differentiated adenocarcinoma and undifferentiated type; poorly differentiated and mucinous adenocarcinoma), operative procedure (laparoscopy and open surgery), operation time, intraoperative EBL, transfusion, intraoperative LMAP and intraoperative LHR. Comorbidities were evaluated according to the Charlson comorbidity index (CCl) [10]. The pathological TNM stage was determined based on the $8^{\text {th }}$ edition of the Union for International Cancer Control TNM classification of malignant tumors [11].

\section{SAS}

We used the original the SAS scoring system to calculate the SAS [4]. The three intraoperative SAS parameters (EBL, LMAP and LHR) were extracted from electronic anesthesia records. The score is the sum of the points from each category (Table 1). The cut-off value of the SAS was determined as the point on the receiver operating characteristic (ROC) curve predicting severe POCs, defined as grade $\geq$ III according to the Clavien-Dindo classification (CDC) [12], at which the Youden index was maximal. All patients were classified into one of two groups based on this cut-off value.

\section{Treatment strategy}

Our treatment strategy for CRC is based on the Japanese Society for Cancer of the Colon and Rectum (JSCCR) guidelines [13]. All patients underwent various radiological tests for the preoperative diagnosis and staging, such as colonoscopy and contrast-enhanced computed tomography (CT). Radical surgery was defined as no residual tumor cells microscopically at the stump of the surgical specimen with an adequate surgical margin. General anesthesia was mainly performed by intravenous anesthesia, and the anesthesiologists were involved in the anesthesia management of all cases. Adjuvant chemotherapy was performed for patients with pathological stage II/III disease. Patients received monotherapy using an oral pro-drug based on 5-FU, such as capecitabine or combination therapy with 5-FU and oxaliplatin, such as 5-fluorouracil/leucovorin plus oxaliplatin (FOLFOX) or capecitabine plus oxaliplatin (CapeOX).

\section{POCs and the prognosis}

Severe POCs were defined as grade $\geq I I I$ according to the CDC that developed within 30 days after surgery. The prognosis was analyzed based on the information in the electronic medical record. Patients were followed up at intervals of three to six months until the end of this study or death. The OS, RFS and CSS were calculated from the start date of the operation to the date of last follow-up or death, to the confirmed date of recurrence or death and to the date of last follow-up or death due to $\mathrm{CRC}$, respectively.

\section{Statistical analyses}

The data of continuous variables are presented as the median (interquartile range [IQR]). The cut-off value of the SAS was calculated by the ROC curve for severe POCs. A univariate analysis was performed by the Mann-Whitney U test for continuous variables and by the chi-squared test for categorical variables. The survival probabilities (the OS, RFS and CSS) were calculated by Kaplan-Meier survival curves and statistically compared by the log-rank test. Univariate and multivariate analyses using the Cox proportional hazard model were performed to identify significant prognostic factors 
for the OS and CSS. Hazard ratios (HRs) and 95\% confidence intervals (Cls) were calculated. Values of $p<0.05$ were considered significant. All data analyses were conducted using the JMP ${ }^{\circledR} 13$ software program (SAS Institute Inc., Cary, NC, USA).

\section{Ethics}

The Ethics Committee at Osaka City University approved this retrospective study of clinical data study, which was conducted in according with the principles of the Declaration of Helsinki.

\section{Results}

\section{Patients' characteristics}

A total of 639 (colon cancer in 460 cases and rectal cancer in 179 cases) patients were enrolled in this study. Severe POCs of CDC grade $\geq$ III were observed in 102 patients (16.0\%). According to the ROC curve analysis, patients were divided into two groups based on the cut-off value of the SAS. The patients with an SAS $\leq 6(n=190,29.7 \%)$ were assigned to the low-SAS group, and those with an SAS $\geq 7(n=449,70.3 \%)$ were assigned to the high-SAS group.

\section{Clinicopathological characteristics of the high-and low-SAS groups}

The low-SAS group more frequently included patients with GPS $\geq 1(p<0.001)$, advanced $\mathrm{pT}(p=0.003)$, advanced pStage $(p=0.005)$, histologically undifferentiated tumor type $(p=0.03)$, open surgery $(p<0.001)$, larger EBL $(p<0.001)$, longer operative time $(p=0.023)$ and transfusion $(p<0.001)$ than the high-SAS group (Table 2$)$.

\section{Postoperative outcomes}

The low-SAS group more frequently included patients with severe POCs (CDC grade $\geq I I I)(p<0.001)$ and who had a significantly longer postoperative stay $(p<0.001)$ than the high-SAS group (Table 2).

\section{The prognosis}

The median follow-up time was 63.4 (IQR, 54.8-83.0) months for all patients. Recurrence was observed in 96 cases (15.0\%). Death due to CRC was observed in 61 cases (9.5\%). A total of 142 deaths (22.2\%) were observed. The 5-year OS, RFS and CSS rates for the entire study population were $82.4 \%, 86.1 \%$ and $91.8 \%$, respectively. Kaplan-Meier survival curves comparing the OS, RFS and CSS between the two groups are shown in Figure 1A-C. The OS, RFS and CSS rates in the low-SAS group were significantly lower than those in the high-SAS group $(p<0.001, p=0.003$, and $p<0.001$, respectively).

\section{Univariate and multivariate analyses for the OS and CSS}

The results of univariate and multivariate analyses for the OS and CSS are summarized in Tables 3 . In the univariate analyses for the OS, age $\geq 75$ years old ( $p<0.001), \mathrm{CCl} \geq 1$ ( $p<0.001)$, GPS $\geq 1(p<0.001)$, ASA-PS $\geq 3(p<0.001)$, open

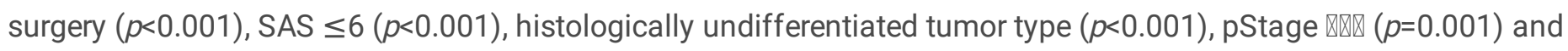
severe POCs ( $p=0.01)$ were significantly associated with a worse OS. In the multivariate analysis for the OS using variables with $p<0.1$ in univariate analyses, age $\geq 75$ years old $(\mathrm{HR}, 2.55 ; 95 \% \mathrm{Cl}, 1.79-3.64 ; p<0.001), \mathrm{CCl} \geq 1(\mathrm{HR}, 1.58$; 95\% Cl, 1.09-2.30; $p=0.015)$, ASA-PS $\geq 3$ (HR, 3.00; 95\% Cl, 1.99-4.49; $p<0.001)$, SAS $\leq 6$ (HR, 1.51; 95\% Cl, 1.04-2.17; $p=0.03)$, histologically undifferentiated tumor type $(\mathrm{HR}, 2.86 ; 95 \% \mathrm{Cl}, 1.58-4.86 ; p<0.001)$ and pStage III $(\mathrm{HR}, 1.90 ; 95 \% \mathrm{Cl}$, $1.33-2.69 ; p<0.001)$ were identified as independent prognostic factors for the OS. In contrast, in the univariate analyses for the CSS, open surgery $(p=0.001)$, SAS $\leq 6(p<0.001)$, rectal cancer $(p=0.016)$, histologically undifferentiated tumor type $(p<0.001)$, pStage $\mathbb{Q}(p<0.001)$, severe POCs $(p=0.029)$ and adjuvant chemotherapy $(p<0.001)$ were significantly 
associated with a worse CSS. In the multivariate analysis for the CSS using variables with $p<0.1$ in univariate analyses, SAS $\leq 6(\mathrm{HR}, 1.88 ; 95 \% \mathrm{Cl}, 1.07-3.30 ; p=0.028)$ and pStage III $(\mathrm{HR}, 5.85 ; 95 \% \mathrm{Cl}, 2.88-12.1 ; p<0.001)$ were identified as independent prognostic factors for the CSS.

\section{Subgroup analyses}

A subgroup analysis according to the presence of severe POCs was conducted. The Kaplan-Meier survival curves comparing the OS based on the SAS in patients with and without severe POCs are shown in Figure 2A, 2B. The OS rates in the low-SAS group were significantly lower than those in the high-SAS group among the patients with and without severe POCs ( $p=0.02$ and $p=0.016$ respectively). A subgroup analysis according to the pStage (I, II and III) was also conducted. The Kaplan-Meier survival curves comparing the OS based on the SAS in patients with pStage I, II and III disease are shown in Figure $3 A-C$. The OS rates in the low-SAS group were significantly lower than those in the high-SAS group among patients with pStage II and III disease ( $p=0.048$ and $p=0.016$ respectively), while no significant difference was seen among the patients with pStage I disease $(p=0.172)$.

\section{Discussion}

In this study, we evaluated the SAS in 639 patients who underwent radical surgery for CRC. We identified a lower SAS $(\leq 6)$ as an independent prognostic factor for the OS and CSS. Nakagawa et al. previously reported that the SAS predicted not only POCs but also the OS in esophageal cancer patients [7], and Yamada et al. reported that the SAS predicted the OS in gastric cancer patients [8]. However, the association between the SAS and oncological outcomes in CRC patients has been unclear. To our knowledge, this is the first study to clarify the impact of the SAS on the RFS and CSS in CRC patients. Our results suggested that the SAS might be a useful biomarker predicting oncological outcomes after radical surgery in CRC patients.

In this study, an older age ( $\geq 75)$, a higher $\mathrm{CCI}(\geq 1)$, a higher ASA-PS $(\geq 3)$, a lower SAS $(\leq 6)$, histologically undifferentiated tumor type and advanced pStage ( $\geq \mathrm{III})$ were identified as independent factors for the OS. Our results were consistent with those of previous studies [14-16]. However, the impact of SAS on the OS has not been fully examined in CRC. An explanation concerning the correlation of the SAS with the OS has been considered. First, the SAS, consists of EBL, LMAP and LHR, reflects intraoperative hemodynamics. Previous studied reported that significant blood loss, intraoperative hypotension and a higher heart rate were associated with a poor prognosis in CRC [17-19]. These studies further indicated that hemodynamic instability might affect the survival in CRC. Second, the SAS reflects surgical stress, as significant blood loss, a large incision and prolonged operation time result in a low SAS. In the present study, a lower SAS was more frequent in patients with more blood loss, open surgery and a longer operation time. Our results were consistent with those of the previous study [20]. Finally, a low SAS was associated with POCs. POCs affect the prognosis in CRC because of marked postoperative inflammation and a poor immunological status [21, 22]. In the present study, a lower SAS was significantly associated with severe POCs. However, regardless of POCs, a lower SAS was significantly associated with a poor OS. Our findings therefore suggest that the SAS might be a useful prognostic marker either with or without POCs in CRC patients.

The oncological significance of the SAS has been poorly documented in CRC patients. A large amount of intraoperative blood loss has been reported to be associated with both tumor cell spillage and immunosuppression, thus leading to cancer recurrence [17]. In addition, a poor intravascular blood flow induces the arrest, adhesion and extravasation of circulating tumor cells preceding metastasis [23]. Furthermore, cancer progression exacerbates the cardiac function [24]. Tumors induce cardiac atrophy and dysfunction through the release of proinflammatory cytokines [25]. In the present study, a lower SAS was significantly associated with an advanced pT, pN and pStage. A lower SAS was significantly associated with a worse RFS and CSS. In particular, a lower SAS was an independent factor for the CSS. These findings 
suggest that the SAS might be a biomarker reflecting not only the intraoperative hemodynamics but also cancer progression in CRC patients.

Postoperative adjuvant chemotherapy using doublet therapy of 5-fluorouracil (5-FU) and folic acid (leucovorin, LV) or capecitabine with oxaliplatin (FOLFOX or CapeOX) has been widely considered the standard treatment for patients with stage III CRC after curative resection [26, 27]. However, $20 \%-30 \%$ of patients with stage III CRC develop recurrence despite receiving adjuvant chemotherapy [28]. This indicates that there remains room for improvement in the outcomes of such patients. Risk factors for recurrence that can help determine the regimen and duration of adjuvant chemotherapy have not been fully validated. In the present study, a subgroup analysis showed that a lower SAS was significantly associated with a worse OS in patients with pStage II and III CRC. These findings suggest that the SAS might be a prognostic biomarker, regardless of the Stage, and may be useful for determining the indication and regimen of adjuvant chemotherapy in CRC patients.

Several limitations associated with the present study warrant mention. First, this study was a retrospective study conducted at a single institution and included patients who underwent both laparoscopic and open surgery, which might have contributed to selection bias. Second, data on anesthesia management, such as the volume of infusions, sedatives and analgesics, were insufficient. Finally, the optimal SAS cut-off value has not yet been determined. The cut-off value in the present study was determined by ROC curve analyses for severe POCs.

\section{Conclusion}

A lower SAS ( $\leq 6)$ was an independent prognostic factor for the OS and CSS after radical surgery in CRC patients. Our results suggest that the SAS might be a useful biomarker predicting oncological outcomes in CRC.

\section{List Of Abbreviations}

CRC, Colorectal cancer; POC, Postoperative complication; SAS, surgical Apgar score; EBL, Estimated blood loss; LMAP, lowest mean arterial pressure; LHR, lowest heart rate; OS, Overall survival; RFS, Recurrence-free survival; CSS, Cancerspecific survival; GIST, gastrointestinal stromal tumor; BMI, body mass index; GPS, Glasgow prognostic score; CRP, Creactive protein; ASA-PS, American Society of Anesthesiologists classification of physical status; $p$ T, Pathological T; pN, pathological N; pStage, Pathological TNM stage; $\mathrm{CCl}$, Charlson comorbidity index; ROC, Receiver operating characteristic; CDC, Clavien-Dindo classification; JSCCR, Japanese Society for Cancer of the Colon and Rectum; CT, Computed tomography, FOLFOX, 5-fluorouracil/leucovorin plus oxaliplatin; CapeOX, Capecitabine plus oxaliplatin; HR, Hazard ratio; $\mathrm{Cl}$, Confidence interval; 5-FU, 5-fluorouracil; LV, Leucovorin.

\section{Declarations}

\section{Ethics approval and consent to participate}

The Ethics Committee at Osaka City University approved this retrospective study of clinical data study, which was conducted in according with the principles of the Declaration of Helsinki.

\section{Consent for publication}

Informed consent was obtained from all individual participants included in the study.

\section{Availability of data and materials}


The datasets generated during and/or analyzed during the current study are not publicly available due to hospital regulations.

\section{Competing interests}

The authors have no conflicts of interest to declare.

Funding

There are no resources of funding to be reported or declared.

Authors' contributions

AS and TF contributed significantly to the study design, data analysis, and drafted the manuscript. HN, MS, YI, MS and YO participated in data collection and assisted with data interpretation. KM and MO critically reviewed and revised the manuscript. All authors read and approved the final manuscript.

\section{Acknowledgements}

We have no acknowledgments.

\section{References}

1. Sung H, Ferlay J, Siegel RL, Laversanne M, Soerjomataram I, Jemal A, Bray F: Global cancer statistics 2020: GLOBOCAN estimates of incidence and mortality worldwide for 36 cancers in 185 countries. CA Cancer J Clin 2021.

2. Boussios S, Ozturk MA, Moschetta M, Karathanasi A, Zakynthinakis-Kyriakou N, Katsanos KH, Christodoulou DK, Pavlidis N: The Developing Story of Predictive Biomarkers in Colorectal Cancer. J Pers Med 2019, 9.

3. Khuri SF, Henderson WG, DePalma RG, Mosca C, Healey NA, Kumbhani DJ, Participants in the VANSQIP: Determinants of long-term survival after major surgery and the adverse effect of postoperative complications. Ann Surg 2005, 242:326-341; discussion 341-323.

4. Gawande AA, Kwaan MR, Regenbogen SE, Lipsitz SA, Zinner MJ: An Apgar score for surgery. J Am Coll Surg 2007, 204:201-208.

5. Regenbogen SE, Bordeianou L, Hutter MM, Gawande AA: The intraoperative Surgical Apgar Score predicts postdischarge complications after colon and rectal resection. Surgery 2010, 148:559-566.

6. Sugimoto A, Fukuoka T, Nagahara H, Shiutani M, Iseki Y, Wang E, Okazaki Y, Tachimori A, Maeda K, Ohira M: The Surgical Apgar Score Predicts Postoperative Complications in Elderly Patients After Surgery for Colorectal Cancer. Am Surg 2021:31348211038576.

7. Nakagawa A, Nakamura T, Oshikiri T, Hasegawa H, Yamamoto M, Kanaji S, Matsuda Y, Yamashita K, Matsuda T, Sumi Y, et al: The Surgical Apgar Score Predicts Not Only Short-Term Complications But Also Long-Term Prognosis After Esophagectomy. Ann Surg Oncol 2017, 24:3934-3946.

8. Yamada T, Tsuburaya A, Hayashi T, Aoyama T, Fujikawa H, Shirai J, Cho H, Sasaki T, Rino Y, Masuda M, Yoshikawa T: Usefulness of Surgical Apgar Score on Predicting Survival After Surgery for Gastric Cancer. Ann Surg Oncol 2016, 23:757-763.

9. Ishizuka M, Nagata H, Takagi K, Horie T, Kubota K: Inflammation-based prognostic score is a novel predictor of postoperative outcome in patients with colorectal cancer. Ann Surg 2007, 246:1047-1051.

10. Charlson ME, Pompei P, Ales KL, MacKenzie CR: A new method of classifying prognostic comorbidity in longitudinal studies: development and validation. J Chronic Dis 1987, 40:373-383. 
11. Brierley J, Gospodarowicz MK, Wittekind C: TNM classification of malignant tumours. Eighth edition. edn. Chichester, West Sussex, UK ; Hoboken, NJ: John Wiley \& Sons, Inc.; 2017.

12. Clavien PA, Barkun J, de Oliveira ML, Vauthey JN, Dindo D, Schulick RD, de Santibanes E, Pekolj J, Slankamenac K, Bassi C, et al: The Clavien-Dindo classification of surgical complications: five-year experience. Ann Surg 2009, 250:187-196.

13. Watanabe T, Itabashi M, Shimada Y, Tanaka S, Ito Y, Ajioka Y, Hamaguchi T, Hyodo I, Igarashi M, Ishida H, et al: Japanese Society for Cancer of the Colon and Rectum (JSCCR) Guidelines 2014 for treatment of colorectal cancer. Int J Clin Oncol 2015, 20:207-239.

14. Arslani N: Influence of gender, ASA physical status, the location of a tumor and stage of the disease on the survival rate in patients with rectal cancer after surgery. Niger J Clin Pract 2020, 23:1514-1516.

15. Aguero F, Murta-Nascimento C, Gallen M, Andreu-Garcia M, Pera M, Hernandez C, Buron A, Macia F: Colorectal cancer survival: results from a hospital-based cancer registry. Rev Esp Enferm Dig 2012, 104:572-577.

16. Ostenfeld EB, Norgaard M, Thomsen RW, Iversen LH, Jacobsen JB, Sogaard M: Comorbidity and survival of Danish patients with colon and rectal cancer from 2000-2011: a population-based cohort study. Clin Epidemiol 2013, 5:6574.

17. Morner ME, Gunnarsson U, Jestin P, Svanfeldt M: The importance of blood loss during colon cancer surgery for longterm survival: an epidemiological study based on a population based register. Ann Surg 2012, 255:1126-1128.

18. Yu HC, Luo YX, Peng H, Wang XL, Yang ZH, Huang MJ, Kang L, Wang L, Wang JP: Association of perioperative blood pressure with long-term survival in rectal cancer patients. Chin J Cancer 2016, 35:38.

19. Anker MS, Ebner N, Hildebrandt B, Springer J, Sinn M, Riess H, Anker SD, Landmesser U, Haverkamp W, von Haehling $\mathrm{S}$ : Resting heart rate is an independent predictor of death in patients with colorectal, pancreatic, and non-small cell lung cancer: results of a prospective cardiovascular long-term study. Eur J Heart Fail 2016, 18:1524-1534.

20. van der Bij GJ, Oosterling SJ, Beelen RHJ, Meijer S, Coffey JC, van Egmond M: The Perioperative Period is an Underutilized Window of Therapeutic Opportunity in Patients With Colorectal Cancer. Annals of Surgery 2009, 249:727-734.

21. Sueda T, Tei M, Yoshikawa Y, Furukawa H, Matsumura T, Koga C, Wakasugi M, Miyagaki H, Kawabata R, Tsujie M, Hasegawa J: Prognostic impact of postoperative intra-abdominal infections after elective colorectal cancer resection on survival and local recurrence: a propensity score-matched analysis. Int J Colorectal Dis 2020, 35:413-422.

22. Zimmermann MS, Wellner U, Laubert T, Ellebrecht DB, Bruch HP, Keck T, Schloricke E, Benecke CR: Influence of Anastomotic Leak After Elective Colorectal Cancer Resection on Survival and Local Recurrence: A Propensity Score Analysis. Dis Colon Rectum 2019, 62:286-293.

23. Follain G, Osmani N, Azevedo AS, Allio G, Mercier L, Karreman MA, Solecki G, Garcia Leon MJ, Lefebvre O, Fekonja N, et al: Hemodynamic Forces Tune the Arrest, Adhesion, and Extravasation of Circulating Tumor Cells. Dev Cel/ 2018, 45:33-52 e12.

24. Kazemi-Bajestani SM, Becher H, Fassbender K, Chu Q, Baracos VE: Concurrent evolution of cancer cachexia and heart failure: bilateral effects exist. J Cachexia Sarcopenia Muscle 2014, 5:95-104.

25. Ausoni S, Calamelli S, Sacca S, Azzarello G: How progressive cancer endangers the heart: an intriguing and underestimated problem. Cancer Metastasis Rev 2020, 39:535-552.

26. Andre T, Boni C, Navarro M, Tabernero J, Hickish T, Topham C, Bonetti A, Clingan P, Bridgewater J, Rivera F, de Gramont A: Improved overall survival with oxaliplatin, fluorouracil, and leucovorin as adjuvant treatment in stage II or III colon cancer in the MOSAIC trial. J Clin Oncol 2009, 27:3109-3116.

27. Haller DG, Tabernero J, Maroun J, Braud Fd, Price T, Cutsem EV, Hill M, Gilberg F, Rittweger K, Schmoll H-J: Capecitabine Plus Oxaliplatin Compared With Fluorouracil and Folinic Acid As Adjuvant Therapy for Stage III Colon 
Cancer. Journal of Clinical Oncology 2011, 29:1465-1471.

28. Shah MA, Renfro LA, Allegra CJ, Andre T, de Gramont A, Schmoll HJ, Haller DG, Alberts SR, Yothers G, Sargent DJ: Impact of Patient Factors on Recurrence Risk and Time Dependency of Oxaliplatin Benefit in Patients With Colon Cancer: Analysis From Modern-Era Adjuvant Studies in the Adjuvant Colon Cancer End Points (ACCENT) Database. $J$ Clin Oncol 2016, 34:843-853.

\section{Tables}

Table 1. The surgical Apgar score

\begin{tabular}{llllll} 
& 0 point & 1 point & 2 points & 3 points & 4 points \\
\hline Estimated blood loss $(\mathrm{mL})$ & $>1000$ & $601-1000$ & $101-600$ & $\leq 100$ & - \\
\hline Lowest mean arterial pressure $(\mathrm{mmHg})$ & $<40$ & $40-54$ & $55-69$ & $\geq 70$ & - \\
\hline Lowest heart rate (beats/min) & $>85$ & $76-85$ & $66-75$ & $56-65$ & $\leq 55$
\end{tabular}

Table 2. Clinicopathological characteristics of the high- and low-SAS groups 


\begin{tabular}{|c|c|c|c|c|c|}
\hline & & All cases & $\begin{array}{l}\text { Group H (SAS } \\
>6 \text { ) }\end{array}$ & Group L (SAS $\leq 6)$ & \\
\hline Characteristics & & $(n=639)$ & $(n=449)$ & $(n=190)$ & $p$ value \\
\hline Age & years, IQR & $69(62-76)$ & $70(62-76)$ & $69(62-75)$ & 0.762 \\
\hline \multirow[t]{2}{*}{ Gender } & Female & 275 & $189(68.7 \%)$ & $86(31.3 \%)$ & 0.46 \\
\hline & Male & 364 & $260(71.4 \%)$ & $104(28.6 \%)$ & \\
\hline BMI & $\mathrm{kg} / \mathrm{m}^{2}, \mathrm{IQR}$ & $\begin{array}{l}22.1 \\
(20.2-24.3)\end{array}$ & $22.4(20.4-24.4)$ & $21.8(19.9-24.2)$ & 0.167 \\
\hline \multirow[t]{2}{*}{ Smoking } & Yes & 235 & $167(71.1 \%)$ & $68(28.9 \%)$ & 0.737 \\
\hline & No & 404 & $282(69.8 \%)$ & $122(30.2 \%)$ & \\
\hline \multirow[t]{2}{*}{$\mathrm{CCl}$} & $<1$ & 335 & $231(69.0 \%)$ & $104(31.0 \%)$ & 0.447 \\
\hline & $\geq 1$ & 304 & $218(71.7 \%)$ & $86(28.3 \%)$ & \\
\hline \multirow[t]{2}{*}{ GPS } & 0 & 536 & $394(73.5 \%)$ & $142(26.5 \%)$ & $<0.001$ \\
\hline & 1,2 & 103 & $55(53.4 \%)$ & $48(46.6 \%)$ & \\
\hline \multirow[t]{3}{*}{ ASA-PS } & 1 & 101 & 71 (70.3 \%) & $30(29.7 \%)$ & 0.8 \\
\hline & 2 & 459 & $325(70.8 \%)$ & $134(29.2 \%)$ & \\
\hline & 3 & 79 & $53(67.1 \%)$ & $26(32.9 \%)$ & \\
\hline \multirow[t]{2}{*}{ Location } & Colon & 460 & $329(71.5 \%)$ & $131(28.5 \%)$ & 0.266 \\
\hline & Rectum & 179 & $120(67.0 \%)$ & $59(33.0 \%)$ & \\
\hline \multirow[t]{4}{*}{ pT } & 1 & 166 & $132(79.5 \%)$ & $34(20.5 \%)$ & 0.003 \\
\hline & 2 & 101 & 76 (75.2 \%) & $25(24.8 \%)$ & \\
\hline & 3 & 255 & $168(65.9 \%)$ & 87 (38.7 \%) & \\
\hline & 4 & 117 & $73(62.4 \%)$ & $44(37.6 \%)$ & \\
\hline \multirow[t]{3}{*}{$\mathrm{pN}$} & 0 & 451 & $326(72.3 \%)$ & $125(27.7 \%)$ & 0.064 \\
\hline & 1 & 129 & $89(69.0 \%)$ & 40 (31.0 \%) & \\
\hline & 2 & 59 & $34(57.6 \%)$ & $25(42.4 \%)$ & \\
\hline \multirow[t]{3}{*}{ pStage } & I & 239 & $186(77.8 \%)$ & $53(22.2 \%)$ & 0.005 \\
\hline & $\|$ & 212 & $140(66.0 \%)$ & $72(34.0 \%)$ & \\
\hline & III & 188 & $123(65.4 \%)$ & 65 (34.6 \%) & \\
\hline \multirow{2}{*}{$\begin{array}{l}\text { Histologically tumor } \\
\text { type }\end{array}$} & Differentiated & 607 & $432(71.2 \%)$ & $175(28.8 \%)$ & 0.03 \\
\hline & Undifferenciated & 32 & $17(53.1 \%)$ & $15(46.9 \%)$ & \\
\hline \multirow{2}{*}{ Procedures } & Laparoscopy & 429 & 348 (81.1 \%) & $81(18.9 \%)$ & $<0.001$ \\
\hline & Open surgery & 210 & $101(48.1 \%)$ & $109(51.9 \%)$ & \\
\hline EBL & $\mathrm{mL}, \mathrm{IQR}$ & $50(20-150)$ & $38(20-80)$ & $168(50-410)$ & $<0.001$ \\
\hline
\end{tabular}




\begin{tabular}{llllll} 
Operative time & min, IQR & $218(175-271)$ & $211(175-266)$ & $234(176-287)$ & 0.023 \\
\hline Transfusion & Yes & 47 & $x$ & $28(59.6 \%)$ & $<0.001$ \\
\hline No & 592 & $430(72.6 \%)$ & $162(27.4 \%)$ & \\
\hline POC & S CDC II & 537 & $393(73.2 \%)$ & $144(26.8 \%)$ & $<0.001$ \\
\hline & $\geq$ CDC III & 102 & $56(54.9 \%)$ & $46(45.1 \%)$ & \\
\hline Postoperative stay & days, IQR & $12(10-18)$ & $12(10-18)$ & $14(11-23)$ & $<0.001$
\end{tabular}

IQR, interquartile range; $\mathrm{BMI}$, body mass index; $\mathrm{CCl}$, Charlson comorbidity index, GPS, Glasgow prognostic score; POC, postoperative complication; CDC, Clavien-Dindo classification.

Table 3. Results of univariate and multivariate analyses for the OS and CSS 


\begin{tabular}{|c|c|c|c|c|c|c|c|c|}
\hline & \multicolumn{4}{|c|}{ Analysis for OS } & \multicolumn{4}{|c|}{ Analysis for CSS } \\
\hline & \multicolumn{2}{|c|}{ Univariate analysis } & \multicolumn{2}{|c|}{ Multivariate analysis } & \multicolumn{2}{|c|}{ Univariate analysis } & \multicolumn{2}{|c|}{ Multivariate analysis } \\
\hline & $\begin{array}{l}\mathrm{HR}(95 \% \\
\mathrm{Cl})\end{array}$ & $\begin{array}{l}\mathrm{p} \\
\text { value }\end{array}$ & $\begin{array}{l}\mathrm{HR}(95 \% \\
\mathrm{Cl})\end{array}$ & $\begin{array}{l}\mathrm{p} \\
\text { value }\end{array}$ & $\begin{array}{l}\mathrm{HR}(95 \% \\
\mathrm{Cl})\end{array}$ & $\begin{array}{l}\mathrm{p} \\
\text { value }\end{array}$ & $\begin{array}{l}\mathrm{HR}(95 \% \\
\mathrm{Cl})\end{array}$ & $\begin{array}{l}\mathrm{p} \\
\text { value }\end{array}$ \\
\hline $\begin{array}{l}\text { Age } \geq 75 \text { vs }<75 \\
\text { (years old) }\end{array}$ & $\begin{array}{l}2.67 \\
(1.90-3.74)\end{array}$ & $<0.001$ & $\begin{array}{l}2.55 \\
(1.79-3.64)\end{array}$ & $<0.001$ & $\begin{array}{l}1.58 \\
(0.91-2.66)\end{array}$ & 0.101 & & \\
\hline Male vs Female & $\begin{array}{l}1.30 \\
(0.93-1.85)\end{array}$ & 0.126 & & & $\begin{array}{l}0.80 \\
(0.48-1.32)\end{array}$ & 0.381 & & \\
\hline $\begin{array}{l}\mathrm{BMI} \geq 25 \text { vs }<25 \\
\left(\mathrm{~kg} / \mathrm{m}^{2}\right)\end{array}$ & $\begin{array}{l}0.90 \\
(0.58-1.36)\end{array}$ & 0.626 & & & $\begin{array}{l}1.50 \\
(0.83-2.57)\end{array}$ & 0.173 & & \\
\hline $\mathrm{CCl} \geq 1$ vs $\mathrm{CCl} 0$ & $\begin{array}{l}1.99 \\
(1.42-2.81)\end{array}$ & $<0.001$ & $\begin{array}{l}1.58 \\
(1.09-2.30)\end{array}$ & 0.015 & $\begin{array}{l}1.00 \\
(0.60-1.65)\end{array}$ & 0.998 & & \\
\hline $\begin{array}{l}\text { GPS } \geq 1 \text { vs GPS } \\
0\end{array}$ & $\begin{array}{l}2.18 \\
(1.47-3.14)\end{array}$ & $<0.001$ & $\begin{array}{l}1.29 \\
(0.85-1.92)\end{array}$ & 0.227 & $\begin{array}{l}1.78 \\
(0.94-3.15)\end{array}$ & 0.074 & $\begin{array}{l}1.16 \\
(0.59-2.17)\end{array}$ & 0.649 \\
\hline $\begin{array}{l}\text { ASA-PS } 3 \text { vs } \\
\text { ASA-PS } 1,2\end{array}$ & $\begin{array}{l}4.09 \\
(2.81-5.85)\end{array}$ & $<0.001$ & $\begin{array}{l}3.00 \\
(1.99-4.49)\end{array}$ & $<0.001$ & $\begin{array}{l}1.89 \\
(0.90-3.56)\end{array}$ & 0.088 & $\begin{array}{l}1.94 \\
(0.90-3.77)\end{array}$ & 0.086 \\
\hline $\begin{array}{l}\text { Open surgery vs } \\
\text { Laparoscopy }\end{array}$ & $\begin{array}{l}1.88 \\
(1.34-2.62)\end{array}$ & $<0.001$ & $\begin{array}{l}1.30 \\
(0.90-1.88)\end{array}$ & 0.164 & $\begin{array}{l}2.35 \\
(1.42-3.90)\end{array}$ & 0.001 & $\begin{array}{l}1.45 \\
(0.82-2.57)\end{array}$ & 0.199 \\
\hline $\begin{array}{l}\text { Operative } \\
\text { time } \geq 218 \text { vs } \\
<218 \text { (min) }\end{array}$ & $\begin{array}{l}1.02 \\
(0.73-1.43)\end{array}$ & 0.901 & & & $\begin{array}{l}1.45 \\
(0.87-2.45)\end{array}$ & 0.157 & & \\
\hline Transfusion & $\begin{array}{l}1.64 \\
(0.94-2.68)\end{array}$ & 0.08 & $\begin{array}{l}0.61 \\
(0.34-1.05)\end{array}$ & 0.075 & $\begin{array}{l}1.65 \\
(0.68-3.39)\end{array}$ & 0.243 & & \\
\hline SAS $\leq 6$ vs $>6$ & $\begin{array}{l}1.81 \\
(1.29-2.53)\end{array}$ & $<0.001$ & $\begin{array}{l}1.51 \\
(1.04-2.17)\end{array}$ & 0.03 & $\begin{array}{l}2.64 \\
(1.60-4.39)\end{array}$ & $<0.001$ & $\begin{array}{l}1.88 \\
(1.07-3.30)\end{array}$ & 0.028 \\
\hline $\begin{array}{l}\text { Rectal cancer vs } \\
\text { Colon cancer }\end{array}$ & $\begin{array}{l}1.09 \\
(0.75-1.55)\end{array}$ & 0.653 & & & $\begin{array}{l}1.89 \\
(1.13-3.13)\end{array}$ & 0.016 & $\begin{array}{l}1.44 \\
(0.82-2.48)\end{array}$ & 0.199 \\
\hline $\begin{array}{l}\text { Undifferenciated } \\
\text { type vs } \\
\text { Differenciated } \\
\text { type }\end{array}$ & $\begin{array}{l}3.17 \\
(1.80-5.19)\end{array}$ & $<0.001$ & $\begin{array}{l}2.86 \\
(1.58-4.86)\end{array}$ & $<0.001$ & $\begin{array}{l}4.85 \\
(2.30-9.22)\end{array}$ & $<0.001$ & $\begin{array}{l}2.06 \\
(0.94-4.12)\end{array}$ & 0.069 \\
\hline $\begin{array}{l}\text { pStage III vs } \\
\text { pStage } \otimes \text { and } \otimes\end{array}$ & $\begin{array}{l}1.78 \\
(1.26-2.49)\end{array}$ & 0.001 & $\begin{array}{l}1.90 \\
(1.33-2.69)\end{array}$ & $<0.001$ & $\begin{array}{l}5.84 \\
(3.45-10.3)\end{array}$ & $<0.001$ & $\begin{array}{l}5.85 \\
(2.88-12.1)\end{array}$ & $<0.001$ \\
\hline $\begin{array}{l}\mathrm{POC} \geq \mathrm{CDC} \| \mathrm{II} \text { vs } \\
\leq \mathrm{CDC} \|\end{array}$ & $\begin{array}{l}1.72 \\
(1.15-2.51)\end{array}$ & 0.01 & $\begin{array}{l}1.51 \\
(0.99-2.25)\end{array}$ & 0.057 & $\begin{array}{l}1.97 \\
(1.08-3.41)\end{array}$ & 0.029 & $\begin{array}{l}1.67 \\
(0.90-2.96)\end{array}$ & 0.104 \\
\hline $\begin{array}{l}\text { Adjuvant } \\
\text { chemotherapy }\end{array}$ & $\begin{array}{l}0.86 \\
(0.60-1.21)\end{array}$ & 0.39 & & & $\begin{array}{l}3.10 \\
(1.86-5.31)\end{array}$ & $<0.001$ & $\begin{array}{l}0.83 \\
(0.42-1.71)\end{array}$ & 0.612 \\
\hline
\end{tabular}

OS, overall survival; CSS, cancer-specific survival; BMI, body mass index; CCl, Charlson comorbidity index; GPS, Glasgow prognostic score;

POC, postoperative complication; CDC; Clavien-Dindo classification.

\section{Figures}



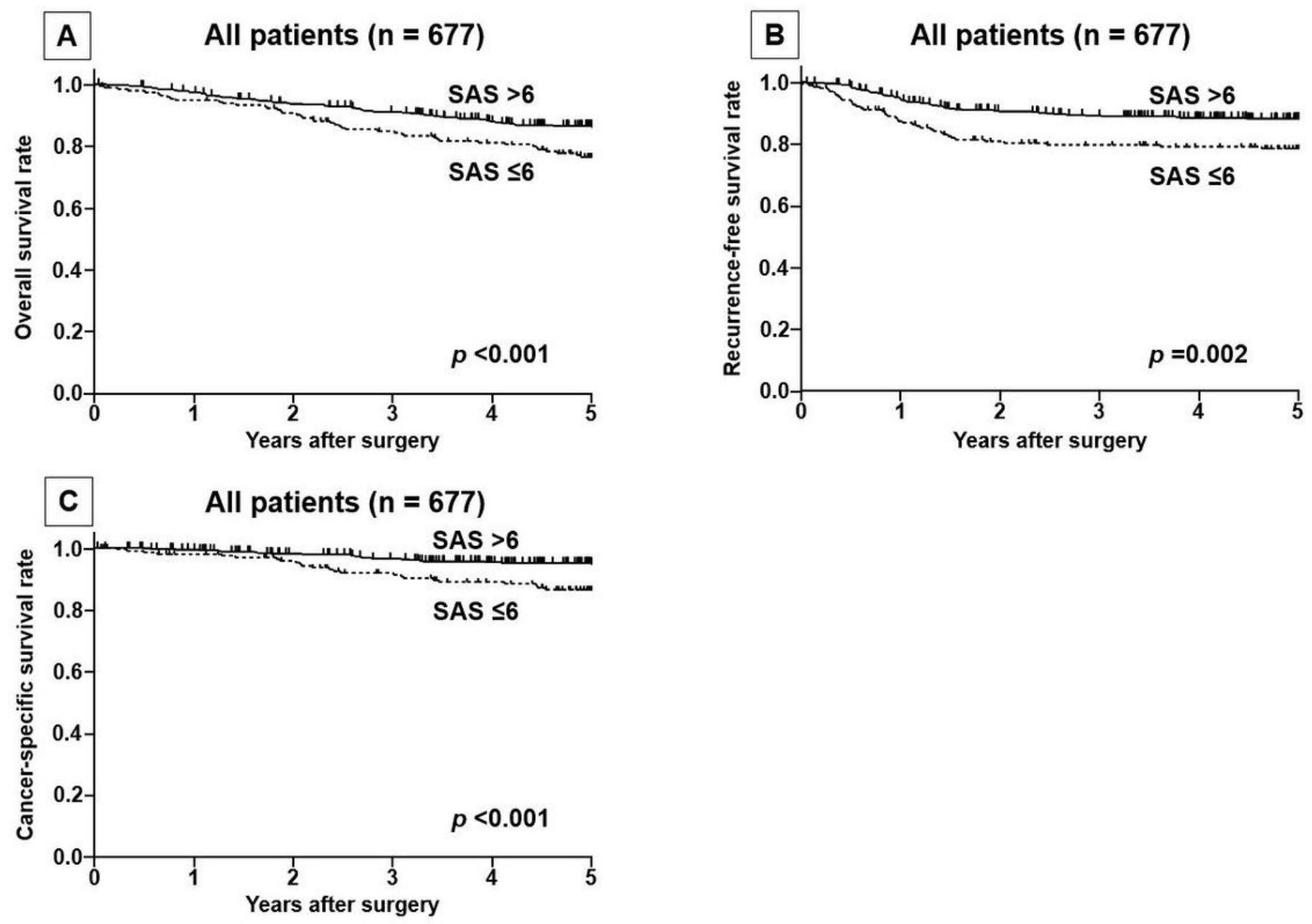

Figure 1

The prognosis based on the surgical Apgar score (SAS). A: The overall survival (OS). The 5-year OS rates in the low-SAS group $(\leq 6)$ were significantly lower than those in the high-SAS group $(\geq 7)(p<0.001)$. B: The recurrence-free survival (RFS). The 5-year RFS rates in the low-SAS group $(\leq 6)$ were significantly lower than those in the high-SAS group $(\geq 7)$ $(p=0.003)$. C: The cancer-specific survival (CSS). The 5-year CSS rates in the low-SAS group $(\leq 6)$ were significantly lower than those in the high-SAS group $(\geq 7)$ (Kaplan-Meier; $\mathrm{p}<0.001)$. 

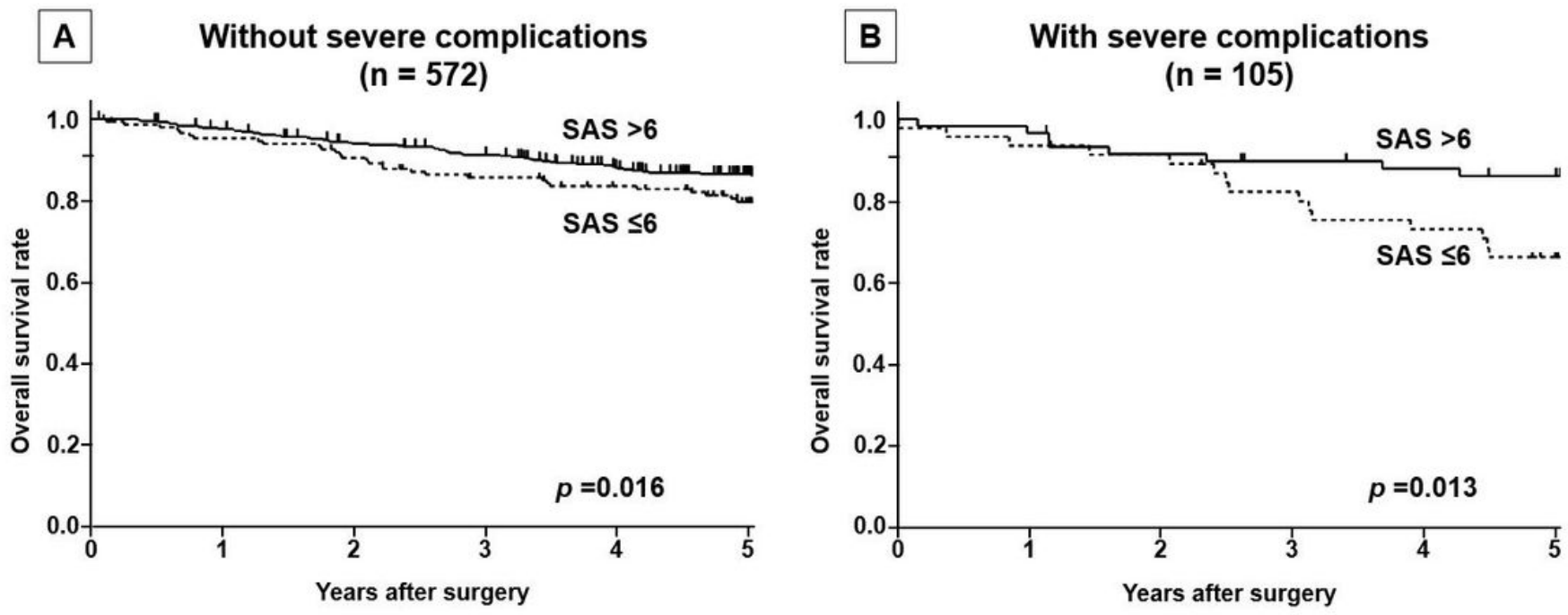

Figure 2

The overall survival (OS) in patients with or without severe complications. A: The OS in 537 patients without severe complications. The OS rates in the low-SAS group $(\leq 6)$ were significantly lower than that in the high-SAS group $(\geq 7)$ $(p=0.016)$. B: The OS in 102 patients with severe complications. The OS rates in the low-SAS group $(\leq 6)$ were significantly lower than that in the high-SAS group $(\geq 7)(p=0.02)$.
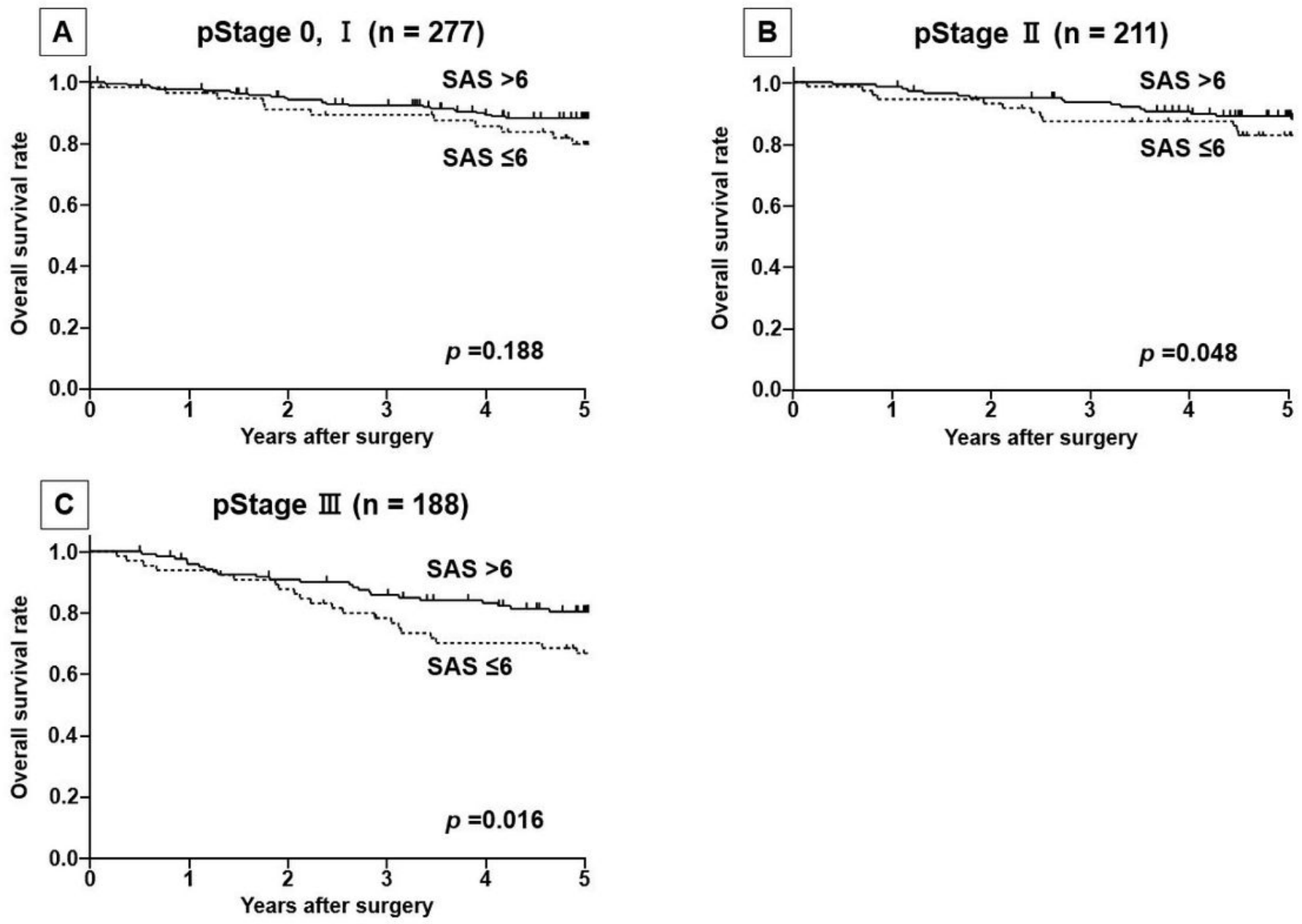


\section{Figure 3}

The overall survival (OS) according to pStage. A: The OS in 239 patients with pStage $\nabla$ colorectal cancer. The OS rates have no significant difference between low SAS $(\leq 6)$ and high SAS $(\geq 7)(p=0.172)$. B: The OS in 211 patients with

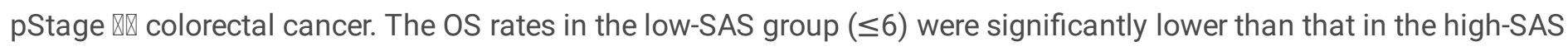
group $(\geq 7)(p=0.048)$. C: The OS in 188 patients with pStage $\|_{\|}$colorectal cancer. The OS rate in the low-SAS group $(\leq 6)$ was significantly lower than that in the high-SAS group $(\geq 7)(p=0.016)$. 